\title{
INNOVATION IN LEARNING PROPORTION USING PROPORTION
}

\section{TABLE}

\author{
Maya Oktaviani \\ Universitas Negeri Jakarta \\ Jalan Rawamangun Muka, Jakarta \\ maya.oktaviani@unj.ac.id
}

\begin{abstract}
This study aims to develop learning of direct and inverse proportion by using proportion tables based on Pendidikan MatematikaRealistik Indonesia (PMRI) approach. Data were collected from preliminary test results, classroom observation, field notes, student activity sheets, test answer sheets, and interviews conducted on students grade VII at Islamic Junior High School Al-Azhar 12 Rawamangun. Based on the results of the retrospective analysis, PMRI characteristics have a role in developing direct and inverse proportion. Students' activities in observing the context presented can train students to develop learning strategies and explore the use of proportion tables. The proportion table can present the students' informal thinking processes and assist students in solving problems related to direct and inverse proportion. The use of student construction results in each meeting contributes to assisting students in understanding the direct and inverse proportion. The conceptual relevance of this study attracts students' attention because the context is given close to student life. Thus, the proportion table can help students to understand the proportion so that they can resolve the proportion problems.
\end{abstract}

Keywords: Direct Proportion, Inverse Proportion, Mathematics Problem, Pendidikan Matematika Realistik Indonesia, Proportion Table

The subject of proportion is one of the subjects taught in elementary school, secondary school, even high school. In secondary school, equivalent fraction often thought as ratio and proportion (Son, 2013, p. 49). Many researches have done, some shown that many students have difficulty developing proportional reasoning. Most of the teachers are teaching proportion with giving the algorithm. Such learning is less meaningful for students. The results of interviews with junior high school teachers stated that students had difficulty in distinguishing direct and inverse proportion. Students are also less skilled in solving proportion problems.

Several studies looked at the proportion learning. Ledesma in her research found the fact that some elementary school students and teachers made mistakes in calculating ratios and proportions. Ledesma presents two rectangles. The first rectangle has a length of $6 \mathrm{~cm}$ and a width of $4 \mathrm{~cm}$, while the second rectangle has a width of $10 \mathrm{~cm}$ and its length is unknown. She asked the teachers to find the length of the second rectangle. The results showed that only 11 out of 23 elementary school teachers could solve the problem (Ledesma, 2011, pp. 265-266).

Proportional reasoning is important for both student and teacher. Students must understand and use a proportion to represent quantitative relationship (NCTM, 2000). Test or assessments use understanding proportion and proportional reasoning as a benchmark entity for students' mathematical proficiency (Arican, 2016, p. 2). Therefore, the teacher needs to teach proportion as well as they learn about it. But a proportion is one subject that difficult to teach (Lobato \&Ellis, 2010, p. 1).

Realistic Mathematics Education (RME) is one approach that can be used in learning direct and inverse proportion. In Indonesia, RME is referred to as Pendidikan MatematikaRealistik Indonesia (PMRI). This is because the PMRI has adjusted to the local cultural context and conditions that occur in Indonesia (Ridhoni, 2013, p. 1). On the other hand, a model that can facilitate students in learning proportion is needed. One of the models that can be used is proportion table. The proportion table shows the proportion clearly because the user can increase the number of columns or rows as needed. The use of 
proportion tables together with context can help students develop reasoning ability about proportion as well as proportion problem-solving strategies.

Based on this background, the question arises, how to develop in learning proportion using proportion table based on PMRI in class VII JHS? This study aims to develop learning of direct and inverse proportion by using proportion tables based on Pendidikan MatematikaRealistik Indonesia (PMRI) approach.

Literature Review Realistic Mathematics Education (RME) was first introduced and developed by Freudenthal in the Netherlands (Zulkardi, 2010). The main principle of RME is that mathematics should be meaningful to students. Indonesia has adapted and developed RME, known as PMRI. PMRI adjusts to the local cultural context and the conditions that occur in Indonesia. There are six characteristics of PMRI: 1) use of contexts for phenomenologist exploration, 2) use of models for mathematical concept construction, 3) use of students' creations and contributions, 4) students' activity and interactivity in the learning process, 5) intertwining mathematics concepts, aspects, and units, and 6) use of typical characteristic of Indonesian nature and cultures (Sembiring, Hoogland, \&Dolk, 2010, p. $160)$.

Mathematics as a human activity demands the exploration of deep and comprehensive phenomena to gain context. Context will lead students to a mathematical understanding of something real (informal) for students into something formal that can be written with symbols through progressive mathematization stages. This study uses story problems with real contexts such as counting army uniforms, making necklaces and bracelets from beads, dividing marbles, and calculating the travel time of Transjakarta buses.

Models and symbols are used to bridge informal mathematics toward formal mathematics through progressive processes. Models are needed as a tool to understand math problems. The proportion table in this study is used as a model that can represent students' informal thinking processes and can assist students in solving problems related to direct and inverse proportion. Through the activities provided by teachers, students are expected to be able to create and contribute to the learning process. Teachers play a role in guiding students to ask questions that require students to think and reflect on the answers. Students who already have construction and production results their self will be confronted with construction and another students' production. The contribution of each student can be used to compare and reflect the benefits of different models. If each student contributes to providing a different model in solving a problem, then the student is then asked to discuss which model is most efficient.

A mathematical topic can be linked to other mathematical topics as to help the interrelationships between topics that can help students understand the concept thoroughly. Mathematical education should be used for integrated knowledge, e.g. theory and application are not taught separately, but theories are developed from problem-solving. PMRI in Indonesia should use characteristics that are appropriate to the natural and local culture of Indonesia. This is expected to be the motivation and the attention of students to learn mathematics. In addition, the use of characteristics of the natural state and local culture of Indonesia as a context can make it easier for students to understand the mathematical concepts being taught.

Langrall\& Swafford said that proportion is a statement of two equal ratios and states the relationship of similarity (2000, p. 255). Son said that a proportion is a statement of the equality of two ratios (2013, p. 50). Based on that, proportion is a variation of two numbers related to each other. In general, the problem of proportion is divided into two, namely missing value problem and comparison problem. Missing value problem presents three known digits and the student is asked to find the fourth number. Comparison problem presents two pairs of numbers or more to compare. In learning proportion at class, the proportion is divided into two, direct and inverse proportion.

The proportion table is considered as an appropriate model for facilitating students in learning proportion. The proportion table shows the proportion clearly because the user 
can increase the number of columns or rows as needed. The real context presented can make students understand what form of count operation should be used in solving the problems at hand. A strategy that can be used in the use of proportion tables to solve proportion problems is shown in the table below.

Table 1. Usage Strategy Proportion Table (Direct Proportion)

\begin{tabular}{|c|c|c|}
\hline \multirow{2}{*}{$\begin{array}{ll} & \text { Strategy } \\
\text { Adding } & \end{array}$} & \multicolumn{2}{|c|}{ Description } \\
\hline & Chocolate & Price \\
\hline & & 6000 \\
\hline & & 3000 \\
\hline & 12 & 9000 \\
\hline \multirow[t]{4}{*}{ Taking away } & Chocolate & Price \\
\hline & & 6000 \\
\hline & 2 & 1500 \\
\hline & 6 & 4500 \\
\hline \multirow[t]{2}{*}{ Multiplying by the same number } & Chocolate & Price \\
\hline & $\times 4\left\{\begin{array}{l}8 \\
32\end{array}\right.$ & $60007 \times 4$ \\
\hline & & \\
\hline \multirow[t]{2}{*}{ Dividing by the same number } & Chocolate & Price \\
\hline & $\div 6\left\{\begin{array}{c}24 \\
4\end{array}\right.$ & $\left.\begin{array}{c}18000 \\
3000\end{array}\right\} \div 6$ \\
\hline
\end{tabular}

Table 2. Usage Strategy Proportion Table (Inverse Proportion)

\begin{tabular}{lccc}
\hline \multicolumn{1}{c}{ Strategy } & \multicolumn{3}{c}{ Description } \\
\hline $\begin{array}{l}\text { Multiplying and dividing by the same } \\
\text { number }\end{array}$ & $\times 2\left\{\begin{array}{rrc}30 & 2 \\
60 & 1\end{array}\right\} \div 2$ & 60 \\
\hline
\end{tabular}

According to Ben-Chaim, Keret, \&llany (2012), proportional reasoning can be used as a marker of the ability to solve proportion problems. When students can find the relationship between two or more variables into a comparison then they can find a solution to the problem based on the proportional reasoning. Abrahamson and Cigan (2003) have also used ratio table or proportion quartet to teach ratios and proportion in grade 5 students. They define multiplication as a recurring sum and use it in ratio tables. The table is used to develop an understanding of the multiplication table.

The local instructional theory in this study is based on previous theories and research. The purpose of this study is to develop learning of direct and inverse proportion by using proportion tables. Therefore, the activities to be conducted in the classroom are designed to introduce a proportion table to the students so that students can use the proportion table in solving the problems related to the proportion.

The sequence of instructional activities that have been designed based on the hypothesis learning trajectory as follows. The first meeting uses activities to observe the clothes of the army with the aim that students can understand the notation of the ratio and introduce the proportion table to the students. The second meeting uses the activity of making necklaces and bracelets of beads for students to be able to understand direct proportion and explore them using a proportion table. The third meeting uses the activity of dividing marbles. Students are asked to find the number of marbles accepted by several children and find the number of children given several marbles. The fourth meeting uses the activity to calculate the travel time of the bus Transjakarta. Both activities were chosen with 
the aim that students understand inverse proportion and explore them using a proportion table. The fifth meeting uses an example and not example activity with the goal of giving students an example of proportion problem and exploring their own knowledge. On this ground, we argue that all these activities were selected could help students understand proportion.

\section{METHOD}

This research was conducted in Islamic Junior High School Al-Azhar 12 Rawamangun. The sample of this research was a class of seventh-grade student. There are six students who will be examined more deeply. Samples were chosen randomly through a simple random sampling method. Data were collected through preliminary test results, classroom observation, field notes, student activity sheets (SAS), test answer sheets, and interviews. Preliminary test data were collected from the students' daily test data on proportion materials and interview results with students and teacher. Class observations are conducted during the learning process by applying local instructional theories in five meetings. At each meeting, discussed different materials such as ratio notation, direct proportion, and inverse proportion. The collection of student activity sheets and answer sheets aims to know the stages of student thinking as well as the level of students' understanding of the subject matter. Interviews with the math teacher who used to teach in the class were conducted before the start of the lesson.

\section{RESULT}

Activities at the first meeting of observing the clothes of the Army. In this activity, students are asked to observe the clothes used by members of the army who are in the ceremony, then students are asked to count the number of berets, shoes, and firearms worn by several members of the army. This activity is chosen with the aim that students can understand the notation of the ratio and introduce the proportion table to the students. This ratio notation will be the basis for students to learn proportions. The context used is also in accordance with the culture of the Indonesian nation. Based on the students' answers, some groups can already fill the proportion table with their respective strategies. Some students find it difficult to determine the number of rows and columns created by some members of the Army.

Students are freed to determine for themselves the number of rows and columns formed by 35 members of the army. Not all students can give a conclusion of this activity. Some of the students are less conscientious in giving conclusions for being fooled by their own answers. After being given individual tests on ratio notation, there are some students who can already understand the rational simplification well.

Activity at the second meeting is making necklaces and bracelets from beads. In this activity, students are asked to count the number of black and white beads required to make several necklaces and bracelets. This activity is chosen with the aim that students can understand the direct proportion and explore it using a proportion table. This activity also emphasizes that to know the number of beads required to make several necklaces or bracelets is the multiplication of a factor with the number of beads required to make a necklace or bracelet. In addition, students can also explore strategies used to determine the number of necklaces or bracelets that can be made with several beads.

Based on the students' answers, some groups can already fill the proportion table with their respective strategies. But there are still groups who find it difficult to find some number of necklace or bracelet if given some beads. Students find it difficult to find the right combination of the number of necklaces and bracelets to be made with the number of black and white beads that have been provided. Nevertheless, all students can finally find the 
answer. In conclusion, there are some students who have been able to determine that the number of necklaces or bracelets that are made directly proportional to the number of beads. After being given individual tests on direct proportion, some students can solve these problems with proportion table.

Activity at the third meeting is dividing marbles. In this activity, students are asked to find the number of marbles received by several children and find the number of children given several marbles. This activity is the introduction of the inverse proportion. This activity is chosen with the aim that students can understand the inverse proportion and explore them using a proportion table. The number of children is a factor of the total number of marbles available. This context is often encountered by students, so they can easily solve it. Most of them, to get answers to the number of marbles received by each child is by dividing the number of marbles to be shared with the number of friends who come. Meanwhile, to get answers to the number of friends who come that is by dividing the number of marbles to be distributed with the number of marbles received by each child. Thus, the multiplication of the number of friends who come with the number of marbles received by each child is the number of all marbles to be distributed.

Activity at the fourth meeting is to calculate the travel time of Transjakarta bus. In this activity, students are asked to find how much time it takes to reach some distance if speed can vary. This activity is chosen with the aim that students better understand the inverse proportion and explore them using a proportion table. In addition, the context in this activity is in accordance with Indonesian culture. Based on the students' answers, some groups can already fill the proportion table with their respective strategies. To find the time required, some students divide the distance by the average speed of the bus. It also makes them must connect this material with the ability they have before (in this case the ability in the field of Physics). At the previous meeting has been explained about the difference between direct and inverse proportion so that students are not too difficult in filling in conclusions.

The activity at the fifth meeting is to give an example and not an example of proportion. In this activity, students are asked to find things in their daily life that are related to a direct proportion, inverse proportion, or a false proportion. The false proportion is things that are not really related to the proportion but resemble the proportion. In addition, students are given several questions relating to direct proportion, inverse proportion, and a false proportion. This activity is chosen with the aim that students can provide examples and not examples of proportion and explore the knowledge they have.

\section{CONCLUSION}

This objective of the current study was to develop learning of direct and inverse proportion by using proportion tables based on Pendidikan MatematikaRealistik Indonesia (PMRI) approach. The use of learning trajectories determines the ratios concept in this study useful well until students can simplify the ratios. In addition, the use of learning trajectories determines the direct proportion concept using a proportion table model combined with a context close to the student also helps the student in understanding the material provided. During individual tests of the second meeting on direct proportion, students use a variety of strategies. The strategies used show that the proportion table can help students to reason where students who do not use the proportion table are not able to see the error of the process.

Surprisingly, during the study, we discovered there were students who at did not use the proportion table when solve individual test. When the teacher asks the reason, s/he replies that s/he feels more comfortable using her/his usual way. But not all the problems s/he can do that way. Also, when students do not use proportion table, students may make mistakes when placing numbers on the equations they create. On the other hand, when solving a direct proportion problem in the type of missing value problem, some students 
using the proportion table tend to be able to solve correctly. The proportion table shows the comparison clearly. Users can increase the number of columns or rows as needed. But there is a problem that can not only be solved by proportion table only. For example, the inverse proportion problem in the type of missing value problem. After using the proportion table, students are required to use other strategies in getting the answer. Some students only work on this problem to get answers from the proportion table only. On these ground, one can expect that the proportion table can help students to understand the proportion so that they can resolve the proportion problems. This study can help teacher to develop proportion learning with PMRI approach, one of them is using proportion table.

\section{REFERENCES}

Abrahamson, D., \&Cigan, C. (2003). A Design for Ratio and Proportion Instruction. Mathematics Teaching in the Middle School, 8(9). Reston: National Council of Teachers Mathematics.

Arican, M. (2016). Preservice Middle and High School Mathematics Teachers' Strategies when Solving Proportion Problems. International Journal of Science and Mathematics Education, 1-21.

Ben-Chaim, D., Keret, Y.,danIlany, B. (2012). Research and Teaching in Mathematics Teachers' Education (Pre- and In-Service Mathematics Teachers of Elementary and Middle School Classes). Rotterdam: Sense Publisher.

Langrall, C.W., \& Swafford, J. (2000). Three Balloons for Two Dollars: Developing Proportional Reasoning. Mathematics Teaching in the Middle School 6 no 4. Reston: National Council of Teachers of Mathematics.

Ledesma, E.F.R. (2011). Primary and Secondary Teachers' Knowledge, Interpretation, and Approaches to Students Errors about Ratio and Proportion Topics. Creative Education, 2(3), 264-269.

Lobato, J. \& Ellis, A. (2010). Developing essential understanding of ratios, proportions, and proportional reasoning for teaching mathematics: Grades 6-8. Reston: National Council of Teachers of Mathematics.

National Council of Teachers of Mathematics. (2000). Principles and standards for school mathematics. Reston: National Council of Teachers of Mathematics.

Ridhoni, M. (2013). Pembelajaran PMRI. Jurnal. Palembang: UniversitasSriwijaya.

Sembiring, R.K. (2010). Pendidikan MatematikaRealistik Indonesia (PMRI): Perkembangan dan Tantangannya. Journal IndoMS-JME, 1(1), 11-16.

Sembiring, R., Hoogland, K., \&Dolk, M. (2010). A Decade of PMRI in Indonesia. Bandung, Utrecht: Ten Brink, Meppel.

Son, J.W. (2013). How preservice teachers interpret and respond to student errors: ratio and proportion in similar rectangles. Education Studies in Mathematics, 84(1), 49-70.

Zulkardi. (2010). How to Design Mathematics Lessons Based on the Realistic Approach? Online from http://eprints.unsri.ac.id/692/1/rme.html. 